\title{
ASSESSING THE SEASONAL DYNAMICS OF INUNDATION, TURBIDITY AND AQUATIC VEGETATION IN THE AUSTRALIAN WET-DRY TROPICS USING OPTICAL REMOTE SENSING
}

\author{
Ward $^{1 *}$, D.P., Hamilton ${ }^{2}$, S.K., Jardine ${ }^{1}$, T.D., Pettit ${ }^{3}$, N.E, Tews ${ }^{1}$, E.K., Olley ${ }^{1}$, J.M. and \\ Bunn $^{1}$, S.E. \\ ${ }^{1}$ Australian Rivers Institute, Griffith University, Nathan, QLD, 4111 \\ ${ }^{2}$ Kellogg Biological Station and Department of Zoology, Michigan State University, \\ Michigan 49060-9516, USA \\ ${ }^{3}$ Centre of Excellence in Natural Resource Management, University of Western Australia, \\ Perth, WA, 6009
}

*author for correspondence: Email doug.ward@ griffith.edu.au

Ph: 61737353543 ; Fax: 61737357615

\section{ABSTRACT}

Floodplain wetlands in the wet-dry tropics are under increasing pressure from water resource development and there is a need for methods to assess the biophysical dynamics of these extensive and often remote ecosystems. This study assessed the capacity of optical remote sensing methods to monitor the seasonal dynamics of inundation, turbidity and aquatic vegetation cover for a northern Australian savanna catchment. MODIS data were used to map seasonal flood inundation patterns, and Landsat 5 TM data were used to map dry-season waterbody dynamics. A network of water depth loggers and temperature sensors provided ground observations of surface inundation dynamics, and was used to validate the inundation mapping. Post flood waterbody surface area declined by $89 \%$ over the dry season, with $70 \%$ of the decline occurring for Palustrine (floodplain) waterbodies. All aquatic systems became increasingly disconnected as the dry season progressed. Statistical relationships were developed between seasonal measurements of turbidity, aquatic vegetation cover, and Landsat spectral data. Catchment wide predictions showed that turbidity increased, and macrophyte cover decreased for Palustrine and Lacustrine (lake) systems, while Riverine systems became less turbid over the dry season. These results show that, for open savanna landscapes where cloud cover does not limit waterbody detection, optical remote sensing methods can be effectively applied to assess seasonal patterns of inundation and accompanying biophysical dynamics. This provides an effective tool to evaluate the impacts of river flow regime changes from water resource use or climate change in these regions.

Key words: optical remote sensing, tropical savanna, floodplains, waterbodies, turbidity, macrophytes 


\section{INTRODUCTION}

Wet-dry tropical savannas cover about $20 \%$ of the global land surface, primarily in the monsoonal climatic belts north and south of the equator, and sometimes extending into the subtropics (Peel et al, 2007). These systems are characterized by strong seasonality in precipitation, with high river flows and extensive floodplain inundation occurring over an often brief wet season, followed by low to zero flows and waterbody contraction and isolation during the dry season (Cresswell et al, 2009; McDonald \& McAlpine, 1991). The timing, extent, duration, and inter-annual variability of inundation control the exchanges of water and biota between rivers and their floodplains, and the degree of seasonal isolation and desiccation of waterbodies determines the distribution of aquatic refugia that persist during the dry season (Hamilton \& Gehrke, 2005; Junk et al, 1989). Aquatic ecosystems in wet-dry tropical savannas across the world are under increasing pressure from human population growth and climate change (Woinarski et al, 2007). Savanna floodplains and waterbodies are increasingly impacted by multiple anthropogenic stressors such as water extraction, invasive animals, weeds, and the potentially acute impact of climate change on dry season aquatic refugia (Tockner et al, 2010; Vorosmarty et al, 2010). Due to their vast size and remoteness from major cities, these systems tend to be less well understood than temperate ecosystems. Methods for measuring, monitoring and modeling these ecosystems are required to enable changes in these systems to be assessed (Hamilton \& Gehrke, 2005).

Wet-dry tropical savannas that are subject to seasonal inundation exhibit large differences in the length of the wet season, and the amount of rainfall over the dry season (Warfe et al, 2011). For example, major savanna floodplain complexes in South America have wet seasons of 3-6 months with correspondingly long floodplain residence times over extensive areas (Hamilton et al, 2002b; 2004). Compared to other continents, wet-dry tropical savanna systems in northern Australia have a comparatively short summer wet season with high intensity rainfall (Kennard et al, 2010; Petheram et al, 2008), but with very little rainfall occurring over the dry season (Jackson, 1988). Hence the savanna landscapes of the wet-dry tropics of northern Australia require monitoring and assessment approaches that are adaptable to relatively short but extensive floodplain inundation, followed by a long dry seasons where there is a strong net water deficit, often resulting in little surface water left on the landscape by the end of the dry season (Cresswell et al., 2009).

This inundation pattern drives a marked seasonal response in aquatic primary production that ultimately supports aquatic food webs in savanna rivers and floodplains. Although vascular plants often make up a conspicuous proportion of primary production on the floodplain, algae appear to be a more important food source for aquatic consumers in floodplain and river waterbodies (Bunn et al, 2003; Douglas et al, 2005) a conclusion that has also been reached for humid tropical floodplains (Lewis et al, 2000). Critical mediating factors influencing algal production are light attenuation, nutrient availability and temperature (Davies et al, 2008). Light availability in aquatic systems is determined by waterbody morphology, turbidity and 
depth, as well as shading from aquatic and surrounding vegetation (Anthony et al, 2004; Liu et al, 2010). Turbidity due to suspended clays can be a particularly important limiting factor in Australian waters (Hamilton \& Gehrke, 2005). Given the likely importance of local algal production to food webs in these systems, methods are also required to assess water turbidity as well as inundation duration and vegetation (macrophyte) cover.

Optical and radar remote sensing applications for mapping inundation dynamics provide useful approaches for understanding the ecohydrology of floodplain aquatic systems (Frazier \& Page, 2009; Hamilton et al, 2002a; Hess \& Melack, 2003; Khan et al, 2011). In this study, optical remotely sensed data (visible and infrared) combined with hydrological and ecological field measurements was used to develop methods for monitoring the seasonal dynamics of aquatic systems in a savanna river catchment in northern Australia. Our aims were 1) to develop and apply robust remote sensing methods for delineating seasonal inundation dynamics that could be applied over large areas in the absence of intensive ground truthing information; and 2) to explore the seasonal biophysical dynamics of water features by developing empirical relationships between seasonal measurements of turbidity, macrophyte cover, and optical spectral data. These relationships are then applied to predict catchment-wide seasonal distributions of these biophysical features, providing insight to the seasonal dynamics of aquatic habitat conditions.

\section{STUDY AREA}

The Mitchell River catchment study area $\left(71630 \mathrm{~km}^{2}\right)$ is located in northern Queensland, Australia (Figure 1). The wet-dry tropical climate of the catchment is largely controlled by the equatorial southern monsoon (McDonald and McAlpine 1991) and is strongly seasonal with $>80 \%$ of the annual rainfall occurring between the wet season months of December to March. Mean annual rainfall increases from around $600 \mathrm{~mm}$ in the south to over $1200 \mathrm{~mm}$ in the northeast and northwest. High mean annual evapotranspiration leads to annual water deficits across the catchment except in the very wettest of years (Cresswell et al, 2009). The rugged hill terrain in much of the headwater areas, ranging up to $1200 \mathrm{~m}$ elevation, grades to Australia's largest fluvial megafan that dominates the western part of the catchment. Megafans in this region are subject to complex fluvial processes and gully erosion of the alluvial floodplain and megafan deposits are widespread across the tropical savanna catchments in northern Queensland (Brooks et al, 2009). The majority of the catchment is open savanna woodland and grasslands with less than $30 \%$ foliage projective cover (Armston et al, 2004). Catchment land use is dominated by cattle grazing of unimproved savanna woodland and grasslands. Only small areas of intensive agriculture and mining occur in the catchment and the major anthropogenic disturbances are associated with cattle grazing, erosion and fire (Brooks et al, 2009). None of the catchment's river channels in the lower floodplain reaches is impounded (Pusey \& Kennard, 2009) with the most significant channel modifications being dry-season channel road crossings.

\section{AQUATIC HABITAT DESCRIPTION}

The freshwater habitat classification scheme used in this study includes Riverine systems (rivers, streams and channelized water bodies), Lacustrine systems (large water bodies situated in a topographic depression or river channels that are largely open water features), 
and Palustrine systems (floodplains and vegetated wetlands such as swamps, and including small, shallow, permanent or intermittent floodplain water bodies) (Auricht, 2010; Cowardin et al, 1979) (Figure 1). These aquatic systems have different habitat characteristics and the classification is used in this study to compare the seasonal dynamics of each system. The mapping of the aquatic systems used in this study was developed as part of the Queensland Wetland Mapping and Classification program (EPA, 2005), which analyzed Landsat images over a $10 \mathrm{yr}$ period to derive waterbody inundation frequency which was combined with aquatic feature mapping derived from 1:50,000 scale topographic mapping. The Landsat mapping used water signatures defined by Landsat Thematic Mapper (TM) Band 5, along with closely affiliated shadow and greenness signatures in Bands 3, 4 and 5, to map water bodies from images captured in 1991, 1995, 1997, 1999 and 2001 (Knight et al, 2009).

The Riverine system consists of the main Mitchell River channel (up to $2 \mathrm{~km}$ wide in places) and upper catchment tributary channels, as well as a network of large lower catchment distributary channels (e.g., the Nassau and the Scrutton rivers) that cross the floodplain and discharge directly into the Gulf of Carpentaria (Figure 1). Large off-channel Riverine waterbodies associated with the main and distributary channels are found on the megafan floodplain (Brooks et al, 2009). Tributary channels gradually increase in size and have less overhanging vegetation with increasing distance from the headwaters to the mouth. During the wet season, main channel flow occurs as a single macro-channel flow, followed by a contraction to more sinuous flow as islands and bars emerge during the dry season. Connectivity of channels to the floodplain is dependent on river stage, with stage heights from 5 to $20 \mathrm{~m}$ above low water resulting in large losses of river water to overbank discharge onto the floodplain or down the distributary channels (Brooks et al, 2009). At maximum inundation, sheet flow across the floodplain outside of the channels dominates, and flow paths vary according to the distribution of rainfall and the resultant discharge dynamics. During the dry season seawater penetrates well up some of the channels with little or no discharge, and tidal effects can extend further upriver.

Lacustrine (lake) systems ( $>8 \mathrm{ha}$ ) increase in size and abundance on the megafan floodplain in the lower catchment. Only the deepest lakes are perennial and many lakes dry up during the dry season. The floodplain contains many thousands of Palustrine waterbodies (Figure 1) that are filled from either overbank flow from rivers or from local precipitation and runoff (Kennard, 2010). These Palustrine waterbodies range in size from many hectares to very small shallow depressions and almost all are non-perennial or ephemeral with the majority drying up within the first few months of the end of the wet season. Field reconnaissance in the early and late dry season indicated that, as the dry season progresses, Lacustrine and Palustrine floodplain waterbodies contract, become more turbid if they do not dry, and their macrophyte cover within the water and on emergent banks usually declines. Depending on waterbody depth, macrophytes comprise a range of littoral, edge, emergent, submerged, and floating species and become abundant following flood events. There is overhanging vegetation on the Riverine systems, particularly in the upper catchment, however the majority of the Lacustrine and Palustrine water bodies have only fringing overhanging vegetation. 


\section{METHODS}

\section{FIELD SAMPLING}

\section{Physical Measurements}

A network of depth loggers and temperature sensors (used for detecting inundation) was deployed to provide information on the floodplain hydrology of the Mitchell River catchment, and to provide data that could be used to validate the remote sensing. Nine depth loggers (In-Situ LevelTROLL and BaraTROLL pressure transducers; In-Situ Inc.) and 33 temperature sensor (Thermochron iButton) (Hubbart et al, 2005) sites were deployed in the catchment in October 2008 and operated through the 2008/2009 wet season. Loggers and temperature sensors were positioned just above October water levels in the main channel, and tributary and distributary channels. Barometric loggers to correct for local barometric pressure variations were installed in elevated positions within $5 \mathrm{~km}$ of depth logger sites. Depth loggers and temperature sensors were retrieved in June 2009 and depth logger data were corrected for barometric pressure.

The amplitude of diel variation in temperature, derived from the iButton temperature sensors was used as an index of inundation (Hubbart et al, 2005). Temperature sensor sites comprising vertical arrays of three iButton temperature sensors were affixed to trees at elevations suitable for capturing the anticipated range of water levels. An additional control sensor was located in an elevated position within $1 \mathrm{~km}$ of the iButton vertical arrays, and most often at those sites. On retrieval, temperature sensor data were converted to diel ranges as a measure of the degree of inundation-induced damping. To determine a threshold degree of damping of the diurnal temperature range at which sensor inundation occurred, data from iButtons located on the depth loggers were analyzed using Decision Trees (S-PLUS, 1999). Using depth data as a response variable and diurnal temperature range as a predictor, the Decision Tree was reduced to a 2-leaf tree and the first split was used to determine the inundation threshold. The resulting threshold values were checked against iButton control data to assist in validating the derived sensor inundation threshold.

\section{Biological Measurements}

Biological data used in this study included measurements of waterbody macrophyte cover and turbidity. The use of waterbodies by cattle, pigs and horses was monitored by time-lapse cameras (Pettit et al. in review). Sampling of macrophytes and turbidity was conducted at 9 off-channel (Palustrine and Lacustrine) waterbody sites in August and October 2009, and June 2010. Macrophyte sampling comprised three 10-m transects, $50 \mathrm{~m}$ apart at each site. All aquatic plant species within each quadrat were identified, categorized according to their structure as emergent, submerged, floating, and marginal species and their projected foliage cover estimated. Turbidity measurements (NTU) were made at each of the 9 sites over the 3 sample periods using a Hydrolab, Sonde portable water quality meter. An additional 10 Riverine open water turbidity measurements obtained early and late in the 2008 dry season for which it was known that the open water areas had little or no macrophyte cover were also added to the macrophyte and turbidity data set. Turbidity was further analysed in the laboratory using water samples taken at the same time as the Sonde measurements. Time- 
lapse cameras (Moultrie Game Spy, EBSCO Industries, Inc., Alabaster, AL), were mounted on riparian trees and set to automatically take a photograph of the waterbody edge every hour. These cameras were installed at all 9 sites in August 2009, and photos retrieved in October 2009 and June 2010.

\section{Field Spectroradiometry}

Hand held spectroradiometry was undertaken to assist in identifying potential confusion between aquatic end members during the classification process. Field sampled spectral end members included open water with a range of turbidities, wet soil/mud surrounding waterbodies, upland soils, and a range of vegetation covers associated with the margins of the aquatic systems. Spectral sampling was conducted using an ASD FieldSpec® Handheld Pro with a spectral sampling range of $325-1075 \mathrm{~nm}$ (visible to near-infrared). All spectral sampling was conducted using a standard sampling method outlined in Pfitzner et al. (2006) and included white reference (near Lambertain) calibration with each measurement.

\section{SATELLITE IMAGE INUNDATION MAPPING}

\section{Image Analysis Approach}

Infrared (IR) spectral data (>800 nm) is commonly employed in spectral metrics for delineating water features. Using the spectral metrics listed in Table 1, an object-oriented image analysis approach was applied to identify the presence of surface water using the eCognition ${ }^{\circledR}$ Professional Version 7.0 software (Definiens Imaging, Munich). Depth logger and temperature sensor observations were then used to assess the accuracy of the results, and the best performing spectral metric was selected for final water feature delineation. For both the wet-season inundation and dry-season isolation phases, sets of training sites for image classification were developed by combining the Queensland Wetland Mapping and Classification aquatic system mapping and Foliage Projective Cover (FPC) data, and selecting sites that had less than 30\% FPC, and for water features that were large enough to sample without edge effects. The spectral distributions for the training sites were then analyzed and the results used to define sigmoidal fuzzy-logic membership functions in the Definiens image processing software. Areas with greater than $30 \%$ FPC were classified as unknown inundation extent during classification.

\section{Flood inundation phase}

The MODIS Level 1B Calibrated Geolocation Data Set, which has pixel values converted to radiance, was used as the data source for delineating flood water during the flood inundation phase. To maximize the resolution of the flood delineation, only MODIS 250m resolution RED (band 1) and NIR (near infrared) (band 2) bands were used for image segmentation and classification. The segmentation scale factor was chosen such that the resulting image objects were smaller than the width of large channels and waterbodies. To minimize the influence of temporal atmospheric variability during flood image captures, a 'like-values' target based image calibration (Furby \& Campbell, 2001) was performed on all MODIS bands used for flood delineation. Because of the extensive flooding in the Mitchell catchment during the wet season, the only reasonably stable (pseudo) invariant targets are built-up settlements and airstrips that rarely flood. These built-up settlements comprise a range of spectral reflectance 
including vegetation, roads, roof tops and bare ground. Three of the largest built-up settlements with airstrips, including settlements outside the catchment but in the image extent, were used as (pseudo) invariant targets. For each settlement a minimum of 6 MODIS pixels were sampled for each image and the image deemed to be least influenced by atmospheric affects was used as a reference image. Clouds were delineated using a brightness index, and proximity to cloud used to assist in identifying cloud shadows. MODIS cloud masks are available but were not used because there pixel resolution was greater than $250 \mathrm{~m}$.

\section{Waterbody isolation phase}

Post-flood cloud free Landsat TM 5 imagery was captured for March, June and October 2009. Landsat TM pre-processing involved conversion to top-of-atmosphere reflectance units (Chander et al, 2009), correction for earth-sun distance and solar zenith angle, and Dark Object Subtraction (DOS) (Chavez, 1989) to minimize the influence of temporal atmospheric variability. The RED, GREEN, and 3 infrared (IR) Landsat bands were used for image segmentation, and the segmentation scale factor was chosen such that the resulting image objects were smaller than the smallest waterbodies mapped in the Queensland Wetland Mapping and Classification product ( $0.25 \mathrm{ha})$. A waterbody mask was created using the Queensland Wetland Mapping and Classification product. After image classification, the resulting delineated water features were clipped to the waterbody mask to remove areas that may have been incorrectly classified as water features such as burnt areas, or topographic and/or cloud shadows. Waterbody accuracy assessment was only undertaken for March, because after March the water levels were below the installation heights of all the depth loggers and temperature sensors.

\section{ACCURACY ASSESSMENT}

Accuracy assessment for the flood inundation and waterbody isolation phase was conducted using the depth logger - temperature sensor site data. Depth logger - temperature sensor sites were screened for foliage projective cover (FPC), and sites with greater than $30 \%$ FPC were omitted due uncertainty in water detection associated with canopy cover, leaving 20 sites $(\mathrm{N}=20)$ for use in accuracy assessment. Omission, commission and percentage agreement (i.e. number of correctly classified sites / N) was then calculated by overlaying depth logger temperature sensor sites on the delineated flood and waterbody extents for both MODIS and Landsat TM 5 image classifications. The Kappa statistic ( $\kappa)$, which takes into account agreement occurring by chance (Cohen, 1960) was used to calculate water delineation classification accuracy. A particular issue with the behavior and interpretation of the Kappa statistic is the prevalence of the identified trait in the sample population (Feinstein \& Cicchetti, 1990). To minimize costs, the depth logger - temperature sensor sites were not randomly located in the catchment but orientated to capture the maximum flood extent. Because of the rapid recession of flood water in the Mitchell catchment, the resulting identification of water had a prevalence of all water at maximum flood extent or largely no water when the flood receded. This resulted in a prevalence bias in the estimation of the Kappa statistic and so the Kappa statistics reported here are the maximum and minimum Kappa values, $\kappa_{\max }$ and $\kappa_{\min }$ respectively (Lantz \& Nebenzahl, 1996). 


\section{Spectral macrophyte relationship}

Microwave and optical remote sensing have found a range of applications in mapping aquatic vegetation (Adam et al, 2010), particularly for South American floodplains (Costa, 2005; Hamilton et al, 2007; Silva et al, 2008). In this study, regression analysis was applied to develop a relationship between Landsat TM bands and indices, and measured macrophyte cover. Macrophyte cover was estimated from the same sites at three times. However, timelapse photography indicated that the biophysical condition of the waterbodies varied significantly such that the assumption of independence of the errors in least squares regression was met. To test the influence of macrophyte growth form (i.e., emergent, floating, submerged and edge species) on the predictive capability of Landsat spectral data, growth form types were regressed against Landsat spectral data for each type individually, and in all combinations. Spectral predictor variables included Landsat spectral bands (except thermal and infrared (band 4)) and calculations of NDVI and NDWI. Automated backward stepwise linear regression (S-PLUS, 1999) was applied to choose the best predictive model (based on the Akaike's Information Criterion for goodness of fit).

\section{Spectral turbidity relationship}

A common approach in the optical modeling of turbidity is to build empirical statistical relationships between in-situ measurements of turbidity and spectral imagery captured by satellites at the time of in-situ measurement (Chen et al, 2007; Doxaran et al, 2002; Miller \& McKee, 2004; Ritchie et al, 1990). In freshwater systems, waterbody imagery captured by satellites can comprise a mixture of water of varying turbidities and varying amounts of macrophyte cover. Field reconnaissance in the early dry season indicated that many shallow off-channel Palustrine waterbodies had sparse but often total water surface coverage of macrophytes. Hence the development of a spectral relationship with measured turbidity must take into account the spectral interference of macrophyte cover on the prediction of turbidity. To address the issue of macrophyte cover in the development of a spectral turbidity relationship, an approach was adopted that included macrophyte cover as well as spectral information as a predictor of turbidity. Turbidity site measurements comprised a combination of 10 open water samples from large waterbodies with no observed macrophyte cover, and 15 samples with measured macrophyte cover. Spectral predictor variables included Landsat spectral bands (except thermal and infrared (band 4)) and calculations of NDVI and NDWI. Automated stepwise linear regression (S-PLUS, 1999) was applied to choose the best model (based on the Akaike's Information Criterion for goodness of fit).

\section{RESULTS}

\section{FIELD SAMPLING}

\section{Physical Measurements}

Flows with depths above dry season logger placements began in the Mitchell main channel on 2 January 2009 and lasted approximately 95 days. Flows in the main distributary channels of the Nassau and Scrutton rivers started 10 days after the main channel flows (Figure 2a). Flow depths exceeded 5 meters leading to overbank discharge for both the Mitchell and the 
Nassau channels with the Nassau distributary channel showing much greater variability in flow depth than the Mitchell channel. Flow depths exceeded $2 \mathrm{~m}$ for the Scrutton and, based on GPS elevation data, would correspond to overbank discharge. Flow depth rose rapidly for the main and distributary channels, and receded rapidly for the distributary channels, both of which had returned to approximately dry season water levels 52 days after commencement of flow. It is evident that parts of the floodplain associated with the main Mitchell channel were inundated for at least 70 days, and for 52 days in the vicinity of the Nassau and Scrutton distributary channels.

For the iButton temperature sensor data, the decision tree analysis resulted in a diel temperature range threshold indicator of inundation of approximately $3.5^{\circ} \mathrm{C}$ (Figure $2 \mathrm{~b}$ ). This threshold was applied to all temperature sensor data and an inundation period for each temperate sensor at each site was recorded in a database with the inundation periods for the depth logger data. From the depth logger and diel temperature range data, a depth of approximately $20 \mathrm{~cm}$ was estimated as the depth above which the iButtons could reliably detect the presence of water (Figure $2 b$ ). The depth logger - temperature sensor database was then used with flood image dates to determine if water was present at a site at the time of image capture.

\section{Biological Measurements}

The results of sampling of macrophytes and turbidity at 9 off-channel waterbody sites in August and October 2009, and June 2010 showed increasing turbidity and decreasing macrophyte cover as the dry season progressed (Figure 3a). This finding was supported by visual inspection of the results of time-lapse photography over the sampling period. In contrast, the additional 10 Riverine open water turbidity measurements obtained in 2008 showed a decrease in turbidity from early to late dry. All 9 of-channel waterbody sites had turbidities < 20 NTU in June 2010. The greatest rate of increase in turbidity occurred between August and October 2009, with 7 of the 9 sites experiencing greater than a doubling of turbidity (NTU) over the 2 month period. 4 of the 9 sites had turbidities $>1500$ NTU in October 2009. Macrophyte cover showed an inverse relationship to turbidity, with all but one site showing > 30\% increase in macrophyte cover from October 2009 to June 2010 (Figure $3 b$ ). Counts of cattle numbers derived from the time-lapse photography for off-channel waterbody sites showed a four-fold increase in cattle numbers using the waterbodies between August and October 2009.

\section{Spectroradiometry}

Spectroradiometry data collected for water bodies with a range of turbidities indicated that, for the near-infrared part of the spectrum, there was almost complete absorption for "Low turbidity water", but the water absorption decreased with increasing turbidity (Figure 4). For "High turbidity water" (NTU $>2000$, outside the range of the water quality meter), the water absorption was greater than the other measured end members associated with aquatic systems, except for "Wet grey mud" and "Dry riparian grass" (Figure 4). "Wet grey mud" and "Dry riparian grass" overlapped significantly with "High turbidity water" in the near- 
infrared part of the spectrum. From the data gathered in this study, problems of end member separability are likely to occur when turbidity is greater to 2000 NTU.

\section{SATELLITE IMAGE INUNDATION MAPPING}

\section{Flood inundation phase}

Largely cloud-free MODIS flood imagery was captured on 16th February and 3, 9, and 25 March. All image captures were on the receding limb of the hydrograph with the 16 February capture being just past the peak discharge for the Mitchell and the Nassau rivers (Figure 2a), and hence was close to maximum flood extent for 2009 (Figure 5). The results of the accuracy assessment used to compare flood extents delineated using the spectral metrics (Table 1) showed that R/NIR and NDVI performed similarly but R/NIR performed marginally better overall. Spectral samples were more closely clumped for R/NIR than for NDVI, making the fuzzy-logic membership functions easier to define for R/NIR than for NDVI. Based on the results of the R/NIR flood delineation the maximum flood extent for $16^{\text {th }}$ February was 940,031 ha. The surface extent of the flood receded rapidly with $48 \%$ of the flooded area receding within 15 days to 371,193 ha on the $9^{\text {th }}$ March. By the $9^{\text {th }}$ March, the Nassau and Scrutton distributary channels had receded to largely in-channel flow (Figure 2a). By the $25^{\text {th }}$ March the flood extent had receded to 80,750 ha located mainly on the lower floodplain and estuarine areas (Figure 5). To assist in validating the results of the inundation mapping, a regression of MODIS derived flooded area against stage height for the Mitchell main channel depth logger was developed and showed a strong liner relationship $\left(\mathrm{R}^{2}=0.96\right)$.

\section{Waterbody isolation phase}

Post flood cloud-free Landsat 5 TM imagery covering the entire catchment was captured for 24 and 31 March, 5 and 28 June, and 18 and 27 October 2009. The results of the accuracy assessment used to compare waterbody extents delineated using the spectral metrics (Table 1) showed that G/IR-band 5 and NDWI performed similarly but G/IR-band 5 performed better overall. Total waterbody surface area declined by $89 \%$ from March to October. Palustrine waterbodies had the largest extent of all aquatic systems in March and then declined rapidly by October (Figure 6). Riverine extent was always greater than Lacustrine extent and declined over the dry season. Lacustrine extent declined marginally over the dry season (Figure 6).The spatial dynamics of the surface extent of waterbodies varied between aquatic systems (Figure 7). By June, significant sections of the Riverine systems had become disconnected and by October the Riverine systems had contacted to perennial waterbodies occupying the deeper parts of the main channels (Figure 7). A total of 14,465 individual Palustrine waterbodies were delineated in contrast to 1,210 Lacustrine waterbodies. Palustrine waterbodies underwent rapid lateral contraction with the majority of Palustrine waterbodies being dry by June. The surface area of the deeper Lacustrine systems varied little over the study period.

\section{ACCURACY ASSESSMENT}

The results of the accuracy assessment for the flood inundation phase developed using the depth logger - temperature sensor inundation threshold data indicated that NIR underestimated the flood extent and appeared to delineate less turbid water more effectively 
than very turbid water. R/NIR and NDVI performed similarly in delineating clear and turbid flood water with R/NIR performing best overall. For all image dates and delineation methods, omission errors were greater than commission errors (Table 2). Accuracy varied between dates with an overall mean percentage agreement of $82 \%$ for flood mapping. The results of the accuracy assessment for the waterbody isolation phase indicated that individual Landsat band ratios performed better than indices, with the band ratio G/IR-band 5 performing best at delineating water bodies. Percent agreement for waterbody mapping for March was $80 \%$ (Table 2).

\section{SPECTRAL MACROPHYTE AND TURBIDITY RELATIONSHIPS}

\section{Spectral macrophyte relationship}

Based on field measurements, percentage macrophyte cover (for all growth forms combined) was found to be inversely proportional to the natural log of turbidity $\left(\mathrm{R}^{2}=0.63\right)$ with macrophyte cover decreasing as turbidity increased. The highest prediction accuracy for macrophyte cover using Landsat spectral bands and indices as predictors was found to be a combination of all macrophyte growth forms including submerged species $\left(\mathrm{R}^{2}=0.67\right)$, with NDVI, NIR (band 4) and green $(\mathrm{G})$ as the best combination of predictors (Figure 8a). Landsat based catchment wide average Macrophyte cover predictions for the Mitchell River catchment showed a decrease in cover for Palustrine and Lacustrine waterbodies over the dry season. Predicted macrophyte cover remained approximately constant for Riverine systems (Figure 8b). Predicted Macrophyte cover was greatest for Palustrine waterbodies and least for Riverine waterbodies . However, for Palustrine waterbodies most of the surface water supporting these systems is gone by October (Figure 6).

\section{Spectral turbidity relationship}

The best turbidity regression models with macrophyte cover and Landsat spectral variables as predictors were those with macrophyte cover and NDWI as predictors $\left(\mathrm{R}^{2}=0.89\right)$ (Figure 9a). Landsat based catchment wide average turbidity predictions for the Mitchell catchment showed increasing turbidity for Palustrine and Lacustrine systems over the dry season (Figure $9 b)$. Palustrine systems had the highest predicted average turbidity values, with average turbidity being approximately twice the magnitude of Lacustrine systems. Riverine systems had the highest turbidity at the end of the flood inundation phase followed by a significant decrease in turbidity over the dry season (Figure $9 \mathrm{~b}$ ). These results parallel the results of the field waterbody sampling (Figure $2 \mathrm{a}$ and $\mathrm{b}$ ).

\section{DISCUSSION}

\section{REMOTE SENSING OF SURFACE WATER, TURBIDITY, AND MACROPHYTES}

This study has taken advantage of the open savanna landscape, and the long, mostly cloudfree dry season of northern Australian savannas to utilize the rapid return interval, greater pixel resolution choice, and the capacity to measure water quality provided by optical remote sensing platforms. The methods presented here are generally applicable to northern Australia 
except possibly in the wetter climates of the 'top end' where floodplains have more protracted flood residence times and extensive seasonal macrophyte cover (Finlayson, 1991), more akin to South American floodplain ecosystems (Costa, 2005). For these regions further development of the method is required to incorporate radar technologies that can penetrate cloud (more of a problem in humid climates) and dense vegetation canopies (Hess \& Melack, 2003).

The timing and duration of the wet season inundation and the dry season are regular in wetdry tropical regions, though there can be inter-annual variability in the magnitude of annual flood inundation. Based on a rainfall deficit analysis of a 30-year rainfall record for the Mitchell River catchment, 2009 was classified as a moderately wet year. The Mitchell catchment has similar savanna landscape characteristics and experiences a similar climate to other regions in the wet-dry tropics of Northern Australia. Consequently, the methods presented in this study are largely applicable to the other regions in the wet-dry tropics of Northern Australian, and potentially to other continental savanna regions with similar landscape and seasonal climatic characteristics, which occur in South America and Africa.

An important issue when using optical spectral data for predicting turbidity is associated with confusion in estimating turbidity in clear shallow waterbodies due to light penetration to the bottom of waterbodies (Gilvear et al, 2007). Field survey results indicated that Riverine systems tend to be much less turbid than the Lacustrine and Palustrine systems.

Consequently, there is likely to be greater error in the estimate of turbidity for Riverine systems due to the influence of bottom reflectance (Bustamante et al, 2009). Similarly, there is likely to be a larger overestimate of the macrophyte cover for Riverine systems than Palustrine and Lacustrine systems because of the greater extent and proximity of fringing terrestrial vegetation along Riverine systems. Improvements in methods for assessing the seasonal dynamics of macrophyte cover could be achieved by utilizing a fusion of optical and RADAR technologies (Hamilton et al, 2007; Silva et al, 2010).

The results of this study found that turbidity for Riverine systems is highest following the inundation phase but then declines over the dry season. This contrasts with Palustrine systems, and to lesser extent Lacustrine systems, which were found to increase in turbidity and decrease in macrophyte cover over the dry season. This phenomenon is wide spread on the Mitchell floodplain and occurs every year (pers. Comm. Viv Sinnamon, Kowanyama Aboriginal Land and Natural Resource Management Office). This decline in water quality at the end of dry season has also been found to occur in wet-dry tropical savannas in Africa (Wolanski \& Gereta, 2001) and South America (Lewis Jr et al, 2000). Stock number counts derived from the time-lapse cameras showed a four-fold increase in stock numbers utilizing the waterbodies at the end of the dry season. This increase in stock number indicates that mechanical mixing by stock and feral animals is likely to be a significant contributing factor to increasing turbidity (Gereta \& Wolanski, 1998). Other factors that are likely influencing this marked increase in turbidity is the combination of rapidly decreasing water depth and wind induced particulate re-suspension (Hamilton \& Lewis Jr, 1990). Time-lapse photography showed that stock and feral pigs were utilizing the shallow Palustrine waterbodies to forage on the remaining macrophytes. Hence it is likely that a combination of 
poor light conditions and grazing pressure is contributing to the reduction in macrophyte cover at the end of the dry season.

Remote sensing methods for delineating water features require classification accuracy assessment for method validation. Floods, particularly short duration floods, pose a problem for accuracy assessment because conventional means of accuracy assessment that utilize field sampling or interpretation of airborne imagery are usually not available. This study demonstrates cost effective methods for the ground-based spatio-temporal measurement of flood events using depth logger - temperature sensor networks. This approach provided significant insight into the surface hydrology of the study area, and facilitated accuracy assessment of surface water delineation methods. This assessment of accuracy was then applied to determine the best performing spectral metrics to delineate water features in these types of landscapes. Thus providing some confidence in the future applications of these spectral metrics in similar landscapes but where limited ground truthing information is available.

\section{APPLICATIONS FOR ECOSYSTEM MANAGEMENT}

Remote sensing of the hydrological dynamics of wet-dry tropical savannas provides important information on the biophysical factors that influence aquatic ecosystem characteristics such as connectivity, habitat quality and primary productivity. Inundation extent and duration is a key controlling variable. During the flood phase, extensive areas of the Mitchell megafan become inundated, establishing connectivity between the Riverine systems and the floodplain Palustrine and Lacustrine systems. Stable isotope analysis of aquatic food webs has provided evidence that this Riverine - floodplain connectivity is exploited by large and small fish species in the Mitchell catchment (Jardine et al, 2012). Hence, the flood inundation mapping presented here potentially enables the identification of floodplain areas important for the maintenance of aquatic food webs. The significant loss of aquatic habitat that occurs as the dry season progresses (89\% contraction of surface water in 2009) demonstrates the usefulness of seasonal inundation mapping for identifying critical periods when and where there is a limited availability of aquatic habitat to serve as refugia for the freshwater biota (Sheldon et al, 2010).

The methods developed here for assessing the dynamics of inundation, turbidity and macrophyte cover allow interpretation and inference of the seasonal dynamics of aquatic ecosystem habitats. However, what is needed is an approach to integrate these biophysical measurements such that quantitative assessments of aquatic productivity can be more directly derived. Evidence suggests that many aquatic ecosystems in the wet-dry tropics of northern Australia are nutrient poor (Brodie \& Mitchell, 2005). In nutrient-poor aquatic systems, the aquatic light environment has been shown to be the key driver of new biomass synthesis (e.g. benthic algae) (Karlsson et al, 2009). Approaches that can combine remotely sensed information on aquatic biophysical dynamics with methods to predict aquatic light environments could provide a means of integrating information, such as that presented in this study, to more directly quantify the spatio-temporal distributions of aquatic system habitat quality and productivity. 
In conclusion, the methods developed in this study provide a basis for assessing the spatial and temporal dynamics of biophysical factors that influence the freshwater aquatic habitat connectivity, quality and productivity for wet-dry tropical aquatic systems. The results show that in open savanna landscapes with long, mostly cloud-free dry seasons, optical remote sensing methods can be effectively applied to assess the biophysical characteristics and dynamics of aquatic systems in these regions. This type of information is important for evaluating the potential impacts of climate change and/or the implication of flow regime modifications.

\section{ACKNOWLEDGEMENTS}

The authors thank the Kowanyama Aboriginal Land and Natural Resource Management Office for assistance with field collections. We acknowledge the traditional owners of the country from which the samples were collected in the Mitchell River catchment (Kokominjena, Kokoberra, Kunjen, Western Gugu Yalanji, Mulliridgee, Barbarum, Kuku Djunkan and Gugu Mini). This project was funded by the Tropical River and Coastal Knowledge (TRaCK) program which received major funding for its research through the Australian Government's Commonwealth Environment Research Facilities initiative; the Australian Government's Raising National Water Standards Program; Land and Water Australia; the Fisheries Research and Development Corporation and the Queensland Government's Smart State Innovation Fund.

\section{REFERENCES}

Adam E, Mutanga O, Rugege D. 2010. Multispectral and hyperspectral remote sensing for identification and mapping of wetland vegetation: a review. Wetlands Ecology and Management 18: 281-296. 10.1007/s11273-009-9169-z.

Anthony KRN, Ridd PV, Orpin AR, Larcombe P, Lough J. 2004. Temporal variation of light availability in coastal benthic habitats: Effects of clouds, turbidity, and tides. Limnology and Oceanography 49: 2201-2211.

Armston JD, Danaher TJ, Collett LJ. 2004. A regression approach for mapping woody Foliage Projeciton Cover in Queensland with Landsat data. 12th Australasian Remote Sensing and Photogrammetry Conference. Fremantle, Australia.

Auricht CM. 2010. Towards an Australian National Aquatic Ecosystem Classification: Initial Report on an Attribute Based Classification Scheme, Aquatic Ecosystem Task Group and the Department of Environment, Water, Heritage and the Arts.

Brodie J, Mitchell A. 2005. Nutrients in Australian tropical rivers: changes with agricultural development and implications for receiving environments. Marine and Freshwater Research 56: 279-302. DOI: 10.1071/MF04081.

Brooks AP, Shellberg JG, Knight J, Spencer J. 2009. Alluvial gully erosion: an example from the Mitchell fluvial megafan, Queensland, Australia. Earth Surface Processes and Landforms 34: 1951-1969.

Bunn SE, Davies PM, Winning M. 2003. Sources of organic carbon supporting the food web of an arid zone floodplain river. Freshwater Biology 48: 619-635.

Bustamante J, Pacios F, Diaz-Delgado R, Aragones D. 2009. Predictive models of turbidity and water depth in the Donana marshes using Landsat TM and ETM 
plus images. Journal of Environmental Management 90: 2219-2225.

10.1016/j.jenvman.2007.08.021.

Chander G, Markham BL, Helder DL. 2009. Summary of current radiometric calibration coefficients for Landsat MSS, TM, ETM+, and EO-1 ALI sensors. Remote Sensing of Environment 113: 893-903.

Chavez PSJ. 1989. Radiometric calibration of Landsat Thematic Mapper multispectral images. . Photogrammetric Engineering and Remote Sensing. 55: 1285-1294.

Chen ZQ, Muller-Karger FE, Hu CM. 2007. Remote sensing of water clarity in Tampa Bay. Remote Sensing of Environment 109: 249-259. 10.1016/j.rse.2007.01.002.

Cohen J. 1960. A coefficient of agreement for nominal scales. Educational and Psychological Measurement 20: 37-46. 10.1177/001316446002000104.

Costa M. 2005. Estimate of net primary productivity of aquatic vegetation of the Amazon floodplain using Radarsat and JERS-1. International Journal of Remote Sensing 26: 4527-4536.

Cowardin LM, Carter V, Golet FC, LaRoe ET. 1979. Classification of Wetlands and Deepwater Habitats of the United States., ed. USDot Interior: Fish and Wildlife Service.

Cresswell R, Petheram C, Harrington G, Buettikofer H, Hodgen M, Davies PM. 2009. Chapter 1: Water resources in northern Australia. In Northern Australia Land and Water Science Review. Final Report to the Northern Australia Land and Water Taskforce., ed. P Stone. Canberra, Australia.: CSIRO

Davies PM, Bunn SE, Hamilton SK, David D. 2008. Primary Production in Tropical Streams and Rivers. In Tropical Stream Ecology, pp. 23-42. London: Academic Press

Davranche A, Lefebvre G, Poulin B. 2010. Wetland monitoring using classification trees and SPOT-5 seasonal time series. Remote Sensing of Environment 114: 552-562.

Defries RS, Townshend JRG. 1994. NDVI-derived land cover classifications at a global scale. International Journal of Remote Sensing 15: 3567-3586. 10.1080/01431169408954345.

Douglas MM, Bunn SE, Davies PM. 2005. River and wetland food webs in Australia's wet-dry tropics: general principles and implications for management. Marine and Freshwater Research 56: 329-342.

Doxaran D, Froidefond JM, Lavender S, Castaing P. 2002. Spectral signature of highly turbid waters - Application with SPOT data to quantify suspended particulate matter concentrations. Remote Sensing of Environment 81: 149-161. 10.1016/s0034-4257(01)00341-8.

EPA. 2005. Wetland Mapping and Classification Methodology - Overall Framework - A Method to Provide Baseline Mapping and Classification for Wetlands in Queensland., ed. DoEaR Management. Brisbane, Australia.: Queensland Government.

Feinstein AR, Cicchetti DV. 1990. High agreement but low Kappa. I. The problems of two paradoxes. Journal of Clinical Epidemiology 43: 543-549. 10.1016/08954356(90)90158-l.

Finlayson CM. 1991. Production and major nutrient composition of three grass species on the Magela floodplain, Northern territory, Australia. Aquatic Botany 41: 263280.

Frazier P, Page K. 2009. A reach-scale remote sensing technique to relate wetland inundation to river flow. River Research and Applications 25: 836-849. 10.1002/rra.1183. 
Frazier PS, Page KJ. 2000. Water body detection and delineation with Landsat TM data. Photogrammetric Engineering and Remote Sensing 66: 1461-1467.

Furby SL, Campbell NA. 2001. Calibrating images from different dates to 'like-value' digital counts. Remote Sensing of Environment 77: 186-196. 10.1016/s00344257(01)00205-x.

Gereta E, Wolanski E. 1998. Wildlife-water quality interactions in the Serengeti National Park, Tanzania. African Journal of Ecology 36: 1-14.

Gilvear D, Hunter P, Higgins T. 2007. An experimental approach to the measurement of the effects of water depth and substrate on optical and near infra-red reflectance: a field-based assessment of the feasibility of mapping submerged instream habitat. International Journal of Remote Sensing 28: 2241-2256. 10.1080/01431160600976079.

Hamilton SK, Gehrke PC. 2005. Australia's tropical river systems: current scientific understanding and critical knowledge gaps for sustainable management. Marine and Freshwater Research: 243-252.

Hamilton SK, Kellndorfer J, Lehner B, Tobler M. 2007. Remote sensing of floodplain geomorphology as a surrogate for biodiversity in a tropical river system (Madre de Dios, Peru). Geomorphology 89: 23-38.

Hamilton SK, Lewis Jr WM. 1990. Basin morphology in relation to chemical and ecological characteristics of lakes on the Orinoco River floodplain, Venezuela. Arch. Hydrolobiol. 119: 393-425.

Hamilton SK, Sippel SJ, Melack JM. 2002a. Comparison of inundation patterns among major South American floodplains. J. Geophys. Res. 107: 8038. DOI: 10.1029/2000jd000306.

Hamilton SK, Sippel SJ, Melack JM. 2002b. Comparison of inundation patterns among major South American floodplains. Journal of Geophysical Research-Atmospheres 107: 8038

10.1029/2000jd000306.

Hamilton SK, Sippel SJ, Melack JM. 2004. Seasonal inundation patterns in two large savanna floodplains of South America: the Llanos de Moxos (Bolivia) and the Llanos del Orinoco (Venezuela and Colombia). Hydrological Processes 18: 21032116.

Hess LL, Melack JM. 2003. Remote sensing of vegetation and flooding on Magela Creek Floodplain (Northern Territory, Australia) with the SIR-C synthetic aperture radar. Hydrobiologia 500: 65-82. 10.1023/a:1024665017985.

Hubbart J, Link T, Campbell C, Cobos D. 2005. Evaluation of a low-cost temperature measurement system for environmental applications. Hydrological Processes 19: 1517-1523.

Jackson IJ. 1988. Daily rainfall over Northern Australia: Deviations from the world pattern. International Journal of Climatology 8: 463-476.

Jardine T, Pusey B, Hamilton S, Pettit N, Davies P, et al. 2012. Fish mediate high food web connectivity in the lower reaches of a tropical floodplain river. Oecologia 168: 829-838. 10.1007/s00442-011-2148-0.

Junk WJ, Bayley PB, Sparks RE. 1989. The flood pulse concept in river-floodplain systems. Canadian Special Publications in Fisheries and Aquatic Sciences: 110-127.

Karlsson J, Bystrom P, Ask J, Ask P, Persson L, Jansson M. 2009. Light limitation of nutrient-poor lake ecosystems. Nature 460: 506-509.

Kennard M. 2010. Northern Australia trial of the draft High Conservation Value Aquatic Ecosystems (HCVAE) Framework., Charles Darwin University., Darwin, Australia 
Kennard M, Pusey B, Olden J, Mackay S, Stein J, Marsh N. 2010. Classification of natural flow regimes in Australia to support environmental flow management. Freshwater Biology 55: 171-193.

Khan SI, Hong Y, Wang JH, Yilmaz KK, Gourley JJ, et al. 2011. Satellite Remote Sensing and Hydrologic Modeling for Flood Inundation Mapping in Lake Victoria Basin: Implications for Hydrologic Prediction in Ungauged Basins. Ieee Transactions on Geoscience and Remote Sensing 49: 85-95. 10.1109/tgrs.2010.2057513.

Knight AW, Tindall DR, Wilson BA. 2009. A multitemporal multiple density slice method for wetland mapping across the state of Queensland, Australia. International Journal of Remote Sensing 30: 3365-3392. 10.1080/01431160802562180.

Lantz CA, Nebenzahl E. 1996. Behavior and interpretation of the kappa statistic: Resolution of the two paradoxes. Journal of Clinical Epidemiology 49: 431-434. 10.1016/0895-4356(95)00571-4.

Lewis Jr WM, Hamilton SK, Lasi MM, Rodriguez M, Saunders JFI. 2000. Ecological Determinism on the Orinoco Floodplain. BioScience 50: 68-692.

Lewis WM, Hamilton SK, Lasi MA, Rodriguez M, Saunders JF. 2000. Ecological determinism on the Orinoco floodplain. Bioscience 50: 681-692.

Liu YL, Fei T, Bian M, Corsi F. 2010. Assessment of underwater light climate for Lake Dahuchi using field spectral data and Landsat TM. International Journal of Remote Sensing 31: 1625-1643. 10.1080/01431160903475282.

McDonald NS, McAlpine JM. 1991. Floods and droughts: the northern climate. In MonsoonalAustralia - Landscape, Ecology and Man in the Northern Lowland., ed. CD Haynes, MG Ridpath, MAJ Williams, pp. 19-30. Rotterdam.: Blakema Publishers.

McFeeters SK. 1996. The use of the normalized difference water index (NDWI) in the delineation of open water features. International Journal of Remote Sensing 17: 1425-1432.

Miller RL, McKee BA. 2004. Using MODIS Terra 250 m imagery to map concentrations of total suspended matter in coastal waters. Remote Sensing of Environment 93: 259-266. 10.1016/j.rse.2004.07.012.

Pearson RL, Miller LD. 1972. Remote mapping of standing crop biomass for estimation of the productivity of the short grass Prairie, Pawnee National Grasslands, Colorado. 8th International Symposium on Remote Sensing on Environment, ERIM, pp. 1357-1381. Ann Arbor, Michigan, USA

Peel MC, Finlayson BL, McMahon TA. 2007. Updated world map of the Koppen-Geiger climate classification. Hydrology and Earth System Sciences Discussions 4: 16331644.

Petheram C, McMahon TA, Peel MC. 2008. Flow characteristics of rivers in northern Australia: Implications for development. Journal of Hydrology 357: 93-111.

Pfitzner K, Bollhofer A, Carr G. 2006. A Standard Design for Collecting Vegetation Reference Spectra: Implementation and Implications for Data Sharing. Spatial Science 52: 79-92.

Pusey BJ, Kennard MJ. 2009. Chapter 3: Aquatic ecosystems in northern Australia. In Northern Australia Land and Water Science Review. Final Report to the Northern Australia Land and Water Taskforce, ed. P Stone. Canberra, Australia: CSIRO

Rango A, Salomonson VV. 1974. Regional flood mapping from space. Water Resour. Res. 10: 473-484. 10.1029/WR010i003p00473.

Ritchie JC, Cooper CM, Schiebe FR. 1990. The relationship of mss and tm digital data with suspended sediments, chlorophyll, and temperature in moon lake, 
Mississippi. Remote Sensing of Environment 33: 137-148. 10.1016/00344257(90)90039-o.

Rouse JW, Haas RH, Schell JA, Deering DW. 1973. Monitoring vegetation systems in the Great Plains with ERTS. Proceedings of the Third ERTS Symposium, pp. 309-317. Washington DC

S-PLUS. 1999. S-PLUS 2000 Guide to Statistics. Seattle, WA: Data Analysis Products Division, MathSoft

Sheldon F, Bunn SE, Hughes JM, Arthington AH, Balcombe SR, Fellows CS. 2010. Ecological roles and threats to aquatic refugia in arid landscapes: dryland river waterholes. Marine and Freshwater Research 61: 885-895. 10.1071/mf09239.

Silva TSF, Costa MPF, Melack JM. 2010. Spatial and temporal variability of macrophyte cover and productivity in the eastern Amazon floodplain: A remote sensing approach. Remote Sensing of Environment 114: 1998-2010. 10.1016/j.rse.2010.04.007.

Silva TSF, Costa MPF, Melack JM, Novo EMLM. 2008. Remote sensing of aquatic vegetation: theory and applications. Environmental Monitoring and Assessment 140: $131-145$.

Smith LC. 1997. Satellite remote sensing of river inundation area, stage, and discharge: a review. Hydrological Processes 11: 1427-1439.

Tockner K, Pusch M, Borchardt D, Lorang MS. 2010. Multiple stressors in coupled riverfloodplain ecosystems. Freshwater Biology 55: 135-151.

Vorosmarty CJ, McIntyre PB, Gessner MO, Dudgeon D, Prusevich A, et al. 2010. Global threats to human water security and river biodiversity. Nature 467: 555-561. http://www.nature.com/nature/journal/v467/n7315/abs/nature09440.html\#s upplementary-information.

Warfe DM, Pettit NE, Davies PM, Pusey BJ, Hamilton SK, et al. 2011. The 'wet-dry' in the wet-dry tropics drives river ecosystem structure and processes in northern Australia. Freshwater Biology 56: 2169-2195.

Woinarski J, Mackey B, Nix H, Traill B. 2007. The Nature of Northern Australia: Natural Values, Ecological Processes and Future Prospects. Canberra, Australia: Australian National University, E Press.

Wolanski E, Gereta E. 2001. Water quantity and quality as the factors driving the Serengeti ecosystem, Tanzania. Hydrobiologia 458: 169-180. 10.1023/a:1013125321838. 
Table 1. Infrared based spectral metrics (and associated references) commonly employed for delineating water features. NIR - near infrared band, R - red band, G green band.

SPECTRAL METRIC

Near Infrared

Band Ratio

Normalized Difference

Vegetation Index (NDVI)

Normalized Difference

Water Index (NDWI)
FORMULA

NIR

R / NIR, G/NIR

$(\mathrm{NIR}-\mathrm{R}) /(\mathrm{NIR}+\mathrm{R})$

(Rouse et al, 1973)

(Defries \& Townshend, 1994)

(Davranche et al, 2010)

(McFeeters, 1996)

(Davranche et al, 2010)

Table 2. Percentage omission, commission, percentage agreement, and Kappa statistics for 2009 flood and waterbody delineation for the Mitchell River Catchment.

$\begin{array}{lccccc}\text { Date } & \text { Omission error \% } & \text { Commission error } \% & \text { Agreement \% } & \boldsymbol{\kappa}_{\max } \% & \boldsymbol{\kappa}_{\min } \% \\ \text { MODIS 02/16 } & 10 & 10 & 80 & 67 & 55 \\ \text { MODIS 03/03 } & 15 & 10 & 75 & 60 & 42 \\ \text { MODIS 03/09 } & 10 & 5 & 85 & 74 & 67 \\ \text { MODIS 03/25 } & 10 & 0 & 90 & 82 & 79 \\ \text { Landsat 03/31 } & 0 & 20 & 80 & 67 & 55\end{array}$

